\section{Cellular Physiology} and Biochemistry Published online: November 17, 2015

Accepted: October 14, 2015

\title{
Role of Toll-Like Receptor 3 Gene Polymorphisms in Preeclampsia
}

\author{
Aiping Chen ${ }^{a}$ Congying Lia Jingli Wang ${ }^{\mathrm{b}}$ Han Shad Shunfu Piao $^{c}$ Shiguo Liub,c

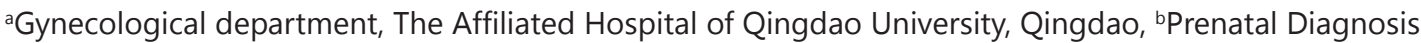 \\ Center, The Affiliated Hospital of Qingdao University, Qingdao, 'Obstetrical department, The Affiliated \\ Hospital of Qingdao University, Qingdao, 'Obstetrical department, Heze Municiple Hospital, Heze, \\ China
}

\section{Key Words}

TLR3 • Polymorphism • Preeclampsia • Chinese

\begin{abstract}
Background/Aims: Accumulating evidence suggests that an excessive maternal systemic inflammatory response to pregnancy with exaggerated activation of the innate immune system plays a critical role in the development of preeclampsia (PE). In this study, we investigated whether polymorphisms in the Toll-like receptor 3 (TLR3) gene are associated with susceptibility to PE in the Chinese Han population. Methods: We recruited 987 PE patients and 1227 healthy pregnant women. Two polymorphisms (rs3775291 and rs3775296) located in TLR3 were genotyped by TaqMan allelic discrimination real-time PCR. The association between the genotype or allele frequencies and PE was examined using chi-square tests. Clinical data were compared between cases and controls using Student's t test. Results: No significant difference was determined in the genetic distribution of rs3775291 and rs3775296 between cases and controls. There were also no significant differences in the genotype and allele frequencies of either SNP between healthy pregnant women and patients with late or early onset PE, or with mild or severe PE. Conclusion: Although this is the first study of the association between TLR3 polymorphisms and preeclampsia, we found that $T L R 3$ polymorphisms are unlikely to play a significant role in the development of preeclampsia in the Chinese Han population.
\end{abstract}

\section{Introduction}

Preeclampsia (PE) is a pregnancy-specific syndrome that usually occurs after 20 weeks gestation. It is determined by increased blood pressure accompanied by proteinuria. The incidence of preeclampsia ranges from $6 \%$ to $8 \%$ of all pregnancies worldwide [1]. As one of the leading causes of maternal and perinatal morbidity and mortality, PE is a severe threat A. Chen and C. Li contributed equally to this work. 
to maternal and infant health. Although numerous studies on the etiology and pathogenesis of PE have been reported, such as inadequate trophoblast invasion [2, 3], placental and endothelial dysfunction [4], immune maladaptation and exaggerated systemic inflammatory response [5, 6], the exact causes of PE remain unclear. Previous studies have also indicated an excessive maternal systemic inflammatory response to pregnancy with exaggerated activation of the innate immune system playing a critical role in the development of PE $[7,8]$.

Toll-like receptor 3 (TLR-3), a member of the toll-like receptor family, recognizes specific pathogen-associated molecular signatures, including dsRNA of viral origin or from dying cells, to activate the innate immune system, which in turn leads to inflammatory responses [9]. Expressed predominantly by innate immune cells, including dendritic cells, macrophages, natural killer cells and mast cells, TLR3 potently activates interferon regulatory factor 3 (IRF3) and nuclear factor-KappaB (NF- $\kappa B$ ), resulting in the release of IFN- $\beta$ and other pro-inflammatory cytokines, such as tumor-necrosis factor (TNF) and interleukin-1 (IL-1) [10-12]. Additionally, activation of TLR3 may induce placental miR-210 via HIF-1 and NF- $\kappa$ B p50, leading to decreased levels of STAT6 and IL-4, which results in increased levels of pro-inflammatory cytokines [13].

PE displays multifactoral inheritance and both environmental risk factors and genetic components influence the development of PE. Although various candidate genes, such as $I F N-\gamma, I L-1$ and TNF- $\alpha$ [14-16], have been shown to have associations with PE, the exact genes involved remain controversial. As important functional variants, TLR3 rs3775296 (in the 5'-UTR) and rs3775291 (in exon 4) polymorphisms affect the expression and cell surface localization of TLR3 and, thereby, influence NF- $\kappa B$ cascade induction [17]. Moreover, polymorphisms in TLR3 have associations with a variety of autoimmune disorders and inflammatory diseases, including systemic lupus erythematosus, sero-negative rheumatoid arthritis (RA), tick-borne encephalitis and multiple types of cancer [18-21]. However, the association between TLR3 polymorphisms and PE has not been investigated. As TLR3 plays a crucial role in the innate immune system, which is excessively activated in PE, we hypothesized that TLR3 genetic variants may affect the susceptibility and clinical symptoms of preeclampsia. In this study, our aim was to investigate whether TLR3 polymorphisms are associated with PE in the Chinese Han population.

\section{Materials and Methods}

\section{Participants}

We collected 987 patients with PE and 1227 healthy pregnant women in their third trimester from The Affiliated Hospital of Qingdao University, The Zaozhuang Maternal and Child Care Service Centre, The Liaocheng People's Hospital. All women were ethnically Chinese Han and healthy controls were enrolled by random selection. The control groups were composed of normal pregnant women, matching the cases according age (maternal age $>26$ years). The mean ages of PE patients and controls were $30.02 \pm 5.89$ years and $30.05 \pm 5.24$ years, respectively. Exclusion criteria of the controls were multifetal gestation, macrosomia, premature rupture of membrane, placenta previa, poly- or oligo-hydramnios, threatened abortion, diabetes mellitus, hypertension and autoimmune disease.

Preeclampsia was defined as the development of hypertension ( $\geq 140 \mathrm{~mm} \mathrm{Hg}$ systolic blood pressure or $\geq 90 \mathrm{~mm} \mathrm{Hg}$ diastolic blood pressure on two or more occasions at least $6 \mathrm{~h}$ apart) and proteinuria ( $\geq$ $300 \mathrm{mg} / 24 \mathrm{~h}, \geq 30 \mathrm{mg} / \mathrm{dL}, \geq 1+$ dipstick proteinuria) that occurred after 20 weeks of gestation in a woman who previously had normal blood pressure $[1,6,22]$. Severe preeclampsia was diagnosed if any of the following criteria was present: blood pressure $\geq 160 / 110 \mathrm{~mm} \mathrm{Hg}$, or proteinuria $\geq 5 \mathrm{~g} / 24 \mathrm{~h}$, or the presence of multiorgan involvement, such as visual or cerebral disturbance, abnormal liver enzymes, oliguria, pain in the epigastric area or right upper quadrant, pulmonary edema or thrombocytopenia (platelet count < $\left.100 \times 10^{9} / \mathrm{L}\right)[1,6,20]$. Early onset of preeclampsia was defined as onset of the disease before 34 weeks of gestation. The study was approved by the Ethics Committee of the Affiliated Hospital of Qingdao University and all the participants gave written informed consent.

\section{KARGER}




\section{Cellular Physiology Cell Physiol Biochem 2015;37:1927-1933

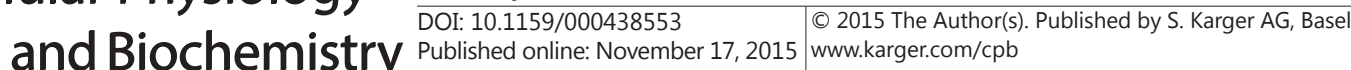 \\ Chen et al. TLR3 Gene Polymorphisms in Preeclampsia}

Genetic studies

Total genomic DNA was extracted from $300 \mu$ l peripheral blood taken for routine laboratory investigations using a Qiagen DNA extraction kit. Two polymorphisms (rs3775291and rs3775296) located in TLR3 were genotyped by TaqMan allelic discrimination real-time PCR. The Taqman probes and primers were designed by Applied Biosystems, Life Technologies. For rs3775291, the primer sequences were: forward, $5^{\prime}$-ACT TGC TCA TTC TCC CTT ACA CATA- $3^{\prime}$ and reverse, $5^{\prime}$-TCA ACC TAA CCA AGA ATA AAA TCTC$3^{\prime}$. For rs3775296, the forward primer was $5^{\prime}$-ACT TTT TAA TGT TTC TTT TCT ACAG- $3^{\prime}$, and reverse primer was 5'-AGA ATC ATG AGA CAG ACT TTG CCTT-3'. The polymerase chain reaction (PCR) mixture contained 20×SNP Genotyping Assay 1.25 $\mu \mathrm{l}, 2 \times$ PCR Master Mix $12.5 \mu \mathrm{l}$, DNA and DNase-free water $11.25 \mu \mathrm{l}$ in a total volume of $25 \mu \mathrm{l}$. The amplifications were carried out on a C1000TM thermal cycler system with the following conditions: $95^{\circ} \mathrm{C}$ for $3 \mathrm{~min}$, followed by 45 cycles at $95^{\circ} \mathrm{C}$ for $15 \mathrm{~s}$ and $60^{\circ} \mathrm{C}$ for $1 \mathrm{~min}$. The fluorescence was detected in real time during PCR thermal cycling. The discrimination of genotypes was conducted with BioRad CFX manager 3.0 software.

\section{Statistical analysis}

Statistical analyses were performed using the software package SPSS21.0. Goodness-of-fit $\chi^{2}$ test was applied to check whether the observed genotype frequencies of the control group were in Hardy-Weinberg equilibrium. Clinical data were compared between cases and controls using Student's t test, and are presented as the mean \pm standard error of the mean. Pearson's $\chi^{2}$ test was performed to compare the allele and genotype frequencies between cases and controls (Fisher's exact test was used when expected values were below 5). For all statistical analyses, a p-value $<0.05$ was considered statistically significant.

\section{Results}

\section{Clinical characteristics}

Clinical characteristics and pregnancy outcomes of cases and controls are presented in Table 1. As compared with controls, preeclampsia patients had earlier delivery $(36.27 \pm 3.09$ weeks vs. $39.33 \pm 1.30$ weeks, $\mathrm{p}<0.001)$, fewer abortions ( $0.66 \pm 0.96$ vs. $0.79 \pm 0.99, \mathrm{P}<$ $0.05)$, lower new-born birth weight $(2622.44 \pm 945.08 \mathrm{~g}$ vs. $3401.92 \pm 373.12 \mathrm{~g}, \mathrm{P}<0.001)$ and higher blood pressure $(\mathrm{P}<0.001)$.

\section{Genetic analysis}

The genetic distribution of rs3775291 and rs3775296 in cases and controls are displayed in Table 2. The control group was in Hardy-Weinberg equilibrium for both SNPs (for rs3775291, $\chi^{2}=1.650, P=0.198$; for rs3775296, $\chi^{2}=0.842, \mathrm{P}=0.359$ ). There were no significant differences in the genotype and allele frequencies of rs3775291 and rs3775296 between cases and controls (for rs3775291, $\chi^{2}=2.120, \mathrm{P}=0.346$ by genotype; $\chi^{2}=0.374, \mathrm{P}$ $=0.541, \mathrm{OR}=1.043,95 \%$ CI $0.911-1.195$ by allele. For $\mathrm{rs} 3775296, \chi^{2}=2.225, \mathrm{P}=0.329$ by genotype; $\chi^{2}=2.26, \mathrm{P}=0.133, \mathrm{OR}=0.9,95 \% \mathrm{CI} 0.789-1.033$ by allele).

To further examine the association between rs3775291 and rs3775296 and PE, the distribution of the two SNPs in preeclamptic subgroups was also investigated. There were no

Table 1. Clinical characteristics

\begin{tabular}{lllll}
\hline & Cases & Controls & $t$ & P-value \\
\hline Age(years) & $30.02 \pm 5.89$ & $30.05 \pm 5.24$ & 0.104 & 0.918 \\
Gestational age(weeks) & $35.44 \pm 3.62$ & $39.05 \pm 1.49$ & 30.537 & $\mathrm{P}<0.001$ \\
Gestational age at delivery (weeks) & $36.27 \pm 3.09$ & $39.33 \pm 1.30$ & 29.298 & $\mathrm{P}<0.001$ \\
Number of abortion & $0.66 \pm 0.96$ & $0.79 \pm 0.99$ & 2.979 & 0.003 \\
Birth weight of offspring (g) & $2622.44 \pm 945.08$ & $3401.92 \pm 373.12$ & 24.55 & $\mathrm{P}<0.001$ \\
Systolic blood pressure (mmHg) & $154.12 \pm 23.22$ & $114.09 \pm 9.95$ & -53.623 & $\mathrm{P}<0.001$ \\
Diastolic blood pressure (mmHg) & $100.65 \pm 16.02$ & $73.33 \pm 7.72$ & -51.771 & $\mathrm{P}<0.001$ \\
\hline
\end{tabular}




\section{Cellular Physiology Cell Physiol Biochem 2015;37:1927-1933

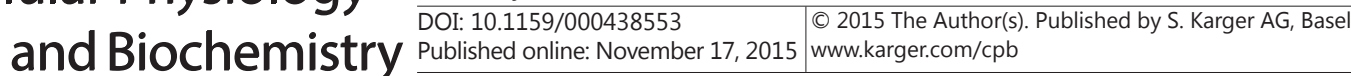 \\ Chen et al.: TLR3 Gene Polymorphisms in Preeclampsia}

Table 2. The genotypic and allelic frequencies of rs3775291 and rs3775296 in cases and controls

\begin{tabular}{llllll}
\hline & Cases & Controls & $\mathrm{X}^{2}$ & P-value & OR(95\%CI) \\
\hline rs3775291 & & & & & \\
Genotypes & & & & & \\
AA & 84 & 85 & 2.120 & 0.346 & \\
AG & 342 & 443 & & & \\
GG & 563 & 699 & & & \\
Alleles & & & & & \\
A & 510 & 613 & 0.374 & 0.541 & $1.043(0.911-1.195)$ \\
G & 1468 & 1841 & & & \\
rs3775296 & & & & & \\
Genotypes & & & & & \\
TT & 59 & 87 & 2.225 & 0.329 & \\
GT & 351 & 456 & & & \\
GG & 579 & 684 & & & \\
Alleles & & & & & \\
T & 469 & 630 & 2.260 & 0.133 & $0.9(0.789-1.033)$ \\
G & 1509 & 1824 & & & \\
\hline
\end{tabular}

Table 3. The comparison of genotype distributions and allelic frequencies between early/late-onset PE and control groups

\begin{tabular}{|c|c|c|c|c|c|c|c|c|c|c|c|}
\hline \multirow[b]{2}{*}{ Group } & \multirow[b]{2}{*}{$\mathrm{N}$} & \multicolumn{5}{|c|}{ rs3775291 } & \multicolumn{5}{|c|}{ rs3775296 } \\
\hline & & $\mathrm{AA}$ & $\mathrm{AG}$ & GG & A & G & GG & GT & TT & G & $\mathrm{T}$ \\
\hline Early-onset PE & 289 & 17 & 94 & 178 & 128 & 450 & 171 & 100 & 18 & 442 & 136 \\
\hline Control & 1227 & 85 & 443 & 699 & 613 & 1841 & 684 & 456 & 87 & 1824 & 630 \\
\hline$\chi^{2}$ & & 2.090 & & & 2.035 & & 1.156 & & & 1.138 & \\
\hline$P$-value & & 0.352 & & & 0.154 & & 0.561 & & & 0.286 & \\
\hline OR & & & & & 0.854 & & & & & 1.123 & \\
\hline $95 \% \mathrm{CI}$ & & & & & $0.688-1.0$ & & & & & $0.908-1.388$ & \\
\hline Late-onset PE & 700 & 65 & 244 & 391 & 374 & 1026 & 414 & 249 & 37 & 1077 & 323 \\
\hline Control & 1227 & 85 & 443 & 699 & 613 & 1841 & 684 & 456 & 87 & 1824 & 630 \\
\hline$\chi^{2}$ & & 3.476 & & & 1.408 & & 3.468 & & & 3.24 & \\
\hline$\hat{P}$-value & & 0.176 & & & 0.235 & & 0.177 & & & 0.072 & \\
\hline OR & & & & & 0.913 & & & & & 0.868 & \\
\hline $95 \% \mathrm{CI}$ & & & & & $0.787-1.0$ & & & & & $0.744-1.013$ & \\
\hline
\end{tabular}

significant differences in the genotype and allele frequencies of either SNP between controls and patients with late and early onset of the disease (shown in Table 3). We also did not find any difference in the genotype and allele frequencies of rs3775291 and rs3775296 between controls and patients with mild and severe PE (displayed in Table 4).

\section{Discussion}

Accumulating evidence has shown that an excessive maternal systemic inflammatory response to pregnancy with exaggerated activation of the innate immune system results in endothelial cell damage, which subsequently leads to the signs and symptoms of PE. TLR3 plays a key role in mediating innate immune responses, as well as in regulating adaptive immunity. TLR3 recognizes dsRNA of viral origin and from endogenous dsRNA that is released from dying cells. This initiates specific signaling pathways, including those leading to the activation of the transcription factors NF- $\mathrm{KB}$ and IRF3. NF- $\mathrm{\kappa B}$ mediates the production of several proinflammatory cytokines, whereas IRF3 regulates the expression of beta interferon (IFN- $\beta$ ), which contributes to the excessive inflammatory response. Moreover, TLR activation may trigger TLR autoamplification feed-forward loops involving circulating 


\section{Cellular Physiology Cell Physiol Biochem 2015;37:1927-1933

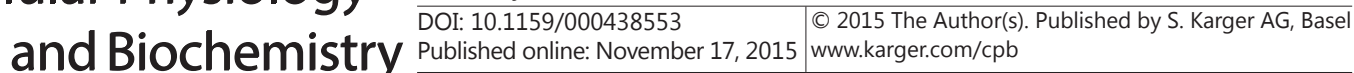 \\ Chen et al.: TLR3 Gene Polymorphisms in Preeclampsia}

Table 4. The comparison of genotype distributions and allelic frequencies between mild/severe PE and control groups

\begin{tabular}{|c|c|c|c|c|c|c|c|c|c|c|c|}
\hline \multirow[b]{2}{*}{ Group } & \multirow[b]{2}{*}{$\mathrm{N}$} & \multicolumn{5}{|c|}{ rs3775291 } & \multicolumn{5}{|c|}{ rs3775296 } \\
\hline & & A & $\mathrm{AG}$ & GG & A & G & GG & GT & TT & G & $\mathrm{T}$ \\
\hline Mild PE & 215 & 21 & 75 & 119 & 117 & 313 & 127 & 78 & 10 & 332 & 98 \\
\hline Control & 1227 & 85 & 443 & 699 & 613 & 1841 & 684 & 456 & 87 & 1824 & 630 \\
\hline$\chi^{2}$ & & 2.168 & & & 0.962 & & 2.016 & & & 1.610 & \\
\hline$P$-value & & 0.338 & & & 0.327 & & 0.365 & & & 0.204 & \\
\hline OR & & & & & 1.123 & & & & & 1.170 & \\
\hline $95 \% \mathrm{CI}$ & & & & & $.891-1$. & & & & & 0.918-1.492 & \\
\hline Severe PE & 774 & 63 & 266 & 445 & 392 & 1156 & 457 & 270 & 47 & 1184 & 364 \\
\hline Control & 1298 & 85 & 443 & 699 & 613 & 1841 & 684 & 456 & 87 & 1824 & 630 \\
\hline$\chi^{2}$ & & 1.370 & & & 0.060 & & 2.320 & & & 2.368 & \\
\hline$P$-value & & 0.504 & & & 0.807 & & 0.313 & & & 0.124 & \\
\hline OR & & & & & 1.018 & & & & & 1.123 & \\
\hline $95 \% \mathrm{CI}$ & & & & & $.880-1$ & & & & & $0.969-1.303$ & \\
\hline
\end{tabular}

leukocytes. The interaction between the maternal endothelium and activated peripheral blood leukocytes [23] would further reduce, or cross, the threshold for the development of clinical preeclampsia [24]. Several studies have shown that TLR3 activation during pregnancy causes preeclampsia-like symptoms indicating that TLR3 plays a key role in the development of PE [25-27].

Our investigation into the effects of two SNPs in TLR3 on the risk of PE in a Chinese Han population failed to detect an association between genotypes or rs3775291 and rs3775296 allele frequencies and PE. Furthermore, no difference was found in the genotype and allele frequencies of the two SNPs between controls and patients with mild and severe PE or with late and early onset of the disease. To our knowledge, this is the first report of the association between TLR3 and susceptibility to PE. This study used relatively large samples, which indicated a low false negative rate; therefore, our results suggest that variants in this genomic region are not associated with preeclampsia. Similar to this conclusion, TLR2 and TLR4 have also been reported to have no association with PE, even though they may play an important role in placental development $[28,29]$.

rs3775291, located in the protein-coding sequence, results in an amino acid substitution, which may reduce or abolish TLR3 activity [17]. Previous studies have shown this SNP to be associated with several inflammatory diseases. Magdalena et al. identified rs3775291 to be significantly associated with RA and suggested a significant association of sero-negative RA with the A allele and disease activity after subgroup analysis [19]. Andrey et al. have reported the frequencies of the rs3775291 G allele, and G/G homozygotes were significantly more numerous among patients with tick-borne encephalitis (TBE) in the Russian population, compared with the control group, especially among patients with severe TBE [30]. However, contrasting results were also observed. Hsin-Yi et al. observed that the rs3775291 has no significant genotype and allele association between osteoarthritis cases and healthy controls in a Chinese Han population [31]. In this study, we did not find an association in the genotype and allele frequencies of rs3775291 between PE patients and healthy pregnant women.

Hsin-Yi et al. have shown that rs3775296, located in the $5^{\prime}$-UTR of TLR3, is associated with elevated TLR3 expression and susceptibility to knee osteoarthritis in a Chinese Han population [31]. Moreover, the rs3775296-T allele was associated with photosensitivity and anemia of system lupus erythematosus in females in a Taiwanese population [32]. However, in the present study, we failed to observe an association between rs3775296 and PE.

In conclusion, no significant difference was found between rs3775291 and rs3775296 in TLR3 and PE in our study. However, there were several limitations that should not be ignored. First, although the sample size of our study was large enough to draw statistically significant conclusions, the Han ethnicity does not represent the entire Chinese population because ethnicity and regional variation play crucial roles. Second, Over 136 SNPs in TLR3 have been identified in the human population, however, only two SNPs were investigated 


\section{Cellular Physiology Cell Physiol Biochem 2015;37:1927-1933 and BiOChemistry \begin{tabular}{l|l} 
DOI: 10.1159/000438553 & (c) 2015 The Author(s). Published by S. Karger AG, Basel \\
www.karger.com/cpb
\end{tabular} \\ Chen et al.: TLR3 Gene Polymorphisms in Preeclampsia}

in our study. Also, complex interactions among genetic and environmental factors cannot be ignored. While PE is generally considered to be a multifactorial disease, environmental interactions may play a role in the pathogenesis of PE. Many environmental factors, including exposure to chemicals, pre-pregnancy weight, height, diet, smoking, and alcohol use may be related to the risk of PE. A limitation of our study is that we did not analyze the interaction and co-morbidity among environmental risk factors, polymorphisms of TLR3 and PE. Therefore, studies with more SNPs and multiple populations are needed to further explore the association between TLR3 polymorphisms and PE.

\section{Acknowledgements}

We thank all subjects for their participation. This work was supported by the National Natural Science Foundation of China (81371499 and 30971586).

\section{Disclosure Statement}

We wish to confirm that there are no known conflicts of interest associated with this publication and that the manuscript has been read and approved by all named authors and that the order of authors listed in the manuscript has been approved by all of us.

\section{References}

1 American College of Obstetricians and Gynecologists: Report of the National High Blood Pressure Education Program Working Group on High Blood Pressure in Pregnancy. Am J Obstet Gynecol 2000;183:S1-S22.

2 Jia RZ, Ding GC, Gu CM, Huang T, Rui C, Wang YX, Lu Q: CDX2 enhances HTR-8/SVneo trophoblast cell invasion by altering the expression of matrix metalloproteinases. Cell Physiol Biochem 2014;34:628-636.

3 Shen Z, Wu Y, Chen X, Chang X, Zhou Q, Zhou J, Ying H, Zheng J, Duan T, Wang K: Decreased maternal serum 2-methoxyestradiol levels are associated with the development of preeclampsia. Cell Physiol Biochem 2014;34:2189-2199.

4 Liu L, Zhang X, Rong C, Rui C, Ji H, Qian YJ, Jia R, Sun L: Distinct DNA methylomes of human placentas between pre-eclampsia and gestational diabetes mellitus. Cell Physiol Biochem 2014;34:1877-1889.

5 Sibai BM: Hypertensive disorders of pregnancy: the United States perspective. Curr Opin Obstet Gynecol 2008;20:102-106.

6 Baha Sibai, Gus Dekker, Michael Kupferminc: Pre-eclampsia. Lancet 2005; 365: 785-799.

7 Redman CW, Sacks GP, Sargent IL: Preeclampsia: an excessive maternal inflammatory response to pregnancy. Am J Obstet Gynecol 1999;180:499-506.

8 Sacks G, Sargent I, Redman C: An innate view of human pregnancy. Immunol Today 1999;20:114-118.

9 Vercammen E, Staal J, Beyaert R: Sensing of viral infection and activation of innate immunity by toll-like receptor 3. Clin Microbiol Rev 2008;21:13-25.

10 Matsumoto M, Kikkawa S, Kohase M, Miyake K, Seya T: Establishment of a monoclonal antibody against human Toll-like receptor 3 that blocks double-stranded RNA-mediated signaling. Biochem Biophys Res Commun 2002;293:1364-1369.

11 Oshiumi H, Matsumoto M, Funami K, Akazawa T, Seya T: TICAM-1, an adaptor molecule that participates in Toll-like receptor 3-mediated interferon-beta induction. Nat Immunol 2003;4:161-167.

12 Yamamoto M, Sato S, Mori K, Hoshino K, Takeuchi O, Takeda K, Akira S: Cutting edge: a novel Toll/IL-1 receptor domain-containing adapter that preferentially activates the IFN-beta promoter in the Toll-like receptor signaling. J Immunol 2002;169:6668-6672.

13 Kopriva SE, Chiasson VL, Mitchell BM, Chatterjee P: TLR3-induced placental miR-210 down-regulates the STAT6/interleukin-4 pathway. PLoS One 2013;8:e67760. 


\section{Cellular Physiology Cell Physiol Biochem 2015;37:1927-1933

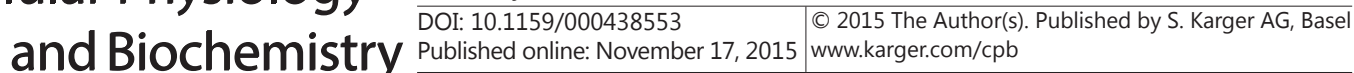 \\ Chen et al.: TLR3 Gene Polymorphisms in Preeclampsia}

14 Pinheiro MB, Gomes KB, Ronda CR, Guimaraes GG, Freitas LG, Teixeira-Carvalho A, Martins-Filho OA, Dusse LM: Severe preeclampsia: association of genes polymorphisms and maternal cytokines production in Brazilian population. Cytokine 2015;71:232-237.

15 Li J, Liu M, Zong J, Tan P, Wang J, Wang X, Ye Y, Liu S, Liu X: Genetic variations in IL1A and IL1RN are associated with the risk of preeclampsia in Chinese Han population. Sci Rep 2014;4:5250.

16 Zubor P, Dokus K, Zigo I, Skerenova M, Pullmann R, Danko J: TNF alpha G308A gene polymorphism has an impact on renal function, microvascular permeability, organ involvement and severity of preeclampsia. Gynecol Obstet Invest 2014;78:150-161.

17 Ranjith-Kumar CT, Miller W, Sun J, Xiong J, Santos J, Yarbrough I, Lamb RJ, Mills J, Duffy KE, Hoose S, Cunningham M, Holzenburg A, Mbow ML, Sarisky RT, Kao CC: Effects of single nucleotide polymorphisms on Toll-like receptor 3 activity and expression in cultured cells. J Biol Chem 2007;282:17696-17705.

18 Laska MJ, Troldborg A, Hansen B, Stengaard-Pedersen K, Junker P, Nexo BA, Voss A: Polymorphisms within Toll-like receptors are associated with systemic lupus erythematosus in a cohort of Danish females. Rheumatology (Oxford) 2014;53:48-55.

19 Laska MJ, Hansen B, Troldborg A, Lorenzen T, Stengaard-Pedersen K, Junker P, Nexo BA, Lindegaard HM: A non-synonymous single-nucleotide polymorphism in the gene encoding Toll-like Receptor 3 (TLR3) is associated with sero-negative rheumatoid arthritis (RA) in a Danish population. BMC Res Notes 2014;7:716.

20 Mickiene A, Pakalniene J, Nordgren J, Carlsson B, Hagbom M, Svensson L, Lindquist L: Polymorphisms in chemokine receptor 5 and Toll-like receptor 3 genes are risk factors for clinical tick-borne encephalitis in the Lithuanian population. PLoS One 2014;9:e106798.

21 Cheng DY, Hao YW, Zhou WL, Ma YR: Association between Toll-like receptor 3 polymorphisms and cancer risk: a meta-analysis. Tumour Biol 2014;35:7837-7846.

22 American College of Obstetricians and Gynecologists: National High Blood Pressure Education Program Working Group Report on High Blood Pressure in Pregnancy. Am J Obstet Gynecol 1990;163:1691-1712.

23 von Dadelszen P, Wilkins T, Redman CWG: Maternal peripheral blood leukocytes in normal and preeclamptic pregnancies. Br J Obstet Gynaecol 1999;106:576-581.

24 Beutler B: Microbe sensing, positive feedback loops, and the pathogenesis of inflammatory diseases. Immunol Rev 2009;227:248-263.

25 Chatterjee P, Chiasson VL, Kopriva SE, Young KJ, Chatterjee V, Jones KA, Mitchell BM: Interleukin 10 Deficiency Exacerbates Toll-Like Receptor 3-Induced Preeclampsia-Like Symptoms in Mice. Hypertension 2011;58:489-U325.

26 Chatterjee P, Kopriva SE, Chiasson VL, Young KJ, Tobin RP, Newell-Rogers K, Mitchell BM: Interleukin-4 deficiency induces mild preeclampsia in mice. J Hypertens 2013;31:1414-1423.

27 Chatterjee P, Weaver LE, Doersch KM, Kopriva SE, Chiasson VL, Allen SJ, Narayanan AM, Young KJ, Jones KA, Kuehl TJ, Mitchell BM: Placental Toll-Like Receptor 3 and Toll-Like Receptor 7/8 Activation Contributes to Preeclampsia in Humans and Mice. PloS One 2012;7:e41884.

28 Franchim CS, Sass N, Mattar R, Pendeloski KPT, Lin LH, Torloni MR, Daher S: Inflammatory Mediators Gene Polymorphisms in Preeclampsia. Hypertens Pregnancy 2011;30:338-346.

29 Molvarec A, Jermendy A, Kovacs M, Prohaszka Z, Rigo J: Toll-like receptor 4 gene polymorphisms and preeclampsia: Lack of association in a Caucasian population. Hypertens Res 2008;31:859-864.

30 Barkhash AV, Voevoda MI, Romaschenko AG: Association of single nucleotide polymorphism rs3775291 in the coding region of the TLR3 gene with predisposition to tick-borne encephalitis in a Russian population. Antiviral Res 2013;99:136-138.

31 Yang HY, Lee HS, Lee CH, Fang WH, Chen HC, Salter DM, Su SL: Association of a functional polymorphism in the promoter region of TLR-3 with osteoarthritis: A two-stage casecontrol study. J Orthop Res 2013;31:680-685.

32 Wang CM, Chang SW, Wu YJJ, Lin JC, Ho HH, Chou TC, Yang B, Wu JM, Chen JY: Genetic variations in Toll-like receptors (TLRs 3/7/8) are associated with systemic lupus erythematosus in a Taiwanese population. Sci Rep 2014;4:3792. 